\title{
IDENTIFICAÇÃO QUÍMICA DA CLOROFENILPIPERAZINA (CPP) EM COMPRIMIDOS APREENDIDOS
}

Rafael Lanaro

Centro de Controle de Intoxicações, Universidade Estadual de Campinas, R. Carlos Chagas, 150- $4^{\circ}$ andar, 13083-970 CampinasSP, Brasil

\section{José Luiz Costa*}

Centro de Exames, Análises e Pesquisas, Instituto de Criminalística, Superintendência da Polícia Técnico Científica do Estado de São Paulo, R. Moncorvo Filho, 410, 05507-060 São Paulo-SP, Brasil

Luiz Antonio Zanolli Filho

Departamento de Química Fundamental, Instituto de Química, Universidade de São Paulo, CP 26077, 05513-970 São Paulo - SP, Brasil Silvia Oliveira Santos Cazenave

Núcleo de Perícias Criminalísticas de Campinas, Superintendência da Polícia Técnico Científica do Estado de São Paulo, R. Barão de Parnaíba, 292, Campinas - SP, Brasil

Recebido em 10/3/09; aceito em 18/8/09; publicado na web em 12/2/10

\begin{abstract}
CHEMICAL IDENTIFICATION OF CHLOROPHENYLPIPERAZINE IN SEIZED TABLETS. Designer drug is a term used to describe psychoactive drugs of abuse which are usually synthesized by modifying the molecular structures of existing drugs of abuse. The term gained widespread popularity when MDMA (ecstasy) experienced a popularity boom in the mid 1980's. In Brazil, designer drugs seizures have increased in the last few years, and actually tablets with unknown psychoactive compounds began to be forwarded to the Forensic Laboratories. This work describes the analytical assays that were performed to identify the chlorophenylpiperazine, a psychoactive substance first time identified in seized tablets in Sao Paulo state.
\end{abstract}

Keywords: chlorophenylpiperazine; mCPP; forensic toxicology.

\section{INTRODUÇÃO}

O consumo mundial de drogas sintéticas de abuso, conhecidas como designer drugs, vem aumentando ano após ano. Estas drogas são comumente produzidas em laboratórios clandestinos, muitas vezes sintetizadas a partir de outras substâncias químicas que já possuam atividade biológica conhecida. Em todo o mundo, a principal representante desta classe de drogas é a 3,4-metilenodioximetanfetamina (MDMA, Ecstasy).

Segundo a Organização das Nações Unidas (ONU), os estimulantes do grupo anfetamínico (amphetamine-type stimulants) estão em segundo lugar na lista de drogas de abuso mais consumidas no mundo, sendo superados apenas pelo uso da maconha. ${ }^{1}$

Apesar da estatística existente, outras substâncias têm sido apreendidas também por serem usadas com finalidade recreativa, como é o caso de derivados da piperazina.

Esses compostos representam uma ampla classe química de substâncias de estrutura cíclica de seis átomos, sendo dois do elemento nitrogênio em posições opostas, como pode ser observado na Figura 1. Muitos derivados da piperazina possuem propriedades farmacológicas importantes, pertencendo a diferentes classes terapêuticas como antifúngicos, antidepressivos, antipsicóticos, antivirais e antagonistas/ agonistas da serotonina (5-HT). ${ }^{2}$

A 1-(3-clorofenil)piperazina (mCPP), popularmente conhecida em alguns países como "X4", rainbow, regenboogies e arc-en-ciel, é uma droga sintética nova cada vez mais comum em países da Europa. ${ }^{3}$ Esta droga foi identificada pela primeira vez na Suécia, em 2004, e desde então já foi apreendida por forças políciais de 26 países daquele continente. Durante o ano de 2006, aproximadamente 823.000 comprimidos de CPP foram apreendidos em países membros da União Europeia. ${ }^{2,3}$

*e-mail: jose.jlc@polcientifica.sp.gov.br.

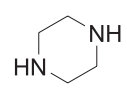

Piperazina<smiles>Clc1cccc(N2CCNCC2)c1</smiles>

1-(3-clorofenil)piperazina (mCPP)

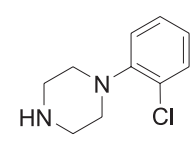

1-(2-clorofenil)piperazina (oCPP)<smiles>Clc1ccc(N2CCNCC2)cc1</smiles>

1-(4-clorofenil)piperazina (pCPP)
Figura 1. Estrutura química da piperazina e seus derivados 1-(2-clorofenil) piperazina (oCPP), 1-(3-clorofenil)piperazina ( $\mathrm{mCPP})$, 1-(4-clorofenil) piperazina $(p C P P)$

A mCPP é consumida normalmente na forma de comprimidos que apresentam aspecto físico muito semelhante aos comprimidos de Ecstasy. A quantidade de substância ativa nestes comprimidos pode variar entre 22 e $80 \mathrm{mg} .{ }^{2,3}$ Alguns autores reportam que os comprimidos de mCPP podem conter diversos diluentes e adulterantes, como MDMA ou cocaína. ${ }^{2-5}$

Outra consideração importante relacionada à mCPP é o fato de que esta substância é um produto de biotransformação ativo do fármaco antidepressivo trazodona, comercializado no Brasil mediante prescrição médica (fármaco sujeito a controle especial). De maneira análoga à trazodona, os efeitos psicoativos da mCPP são relacionados a sua atuação sobre o sistema nervoso central. $\mathrm{O}$ fármaco e o metabólito ativo agem inibindo a recaptação de serotonina e como agonistas deste neurotransmissor. ${ }^{6}$ Além da ação sobre neurônios serotoninérgicos, a mCPP interage ainda com receptores de dopamina, acetilcolina e, também, com os receptores alfa e beta-adrenérgicos. ${ }^{2}$ 
Através da Resolução da Diretoria Colegiada (RDC) n.79, publicada no Diário Oficial da União em 04/11/2008, esta substância foi adicionada à lista F2 da Portaria no 344-98 da Agência Nacional de Vigilância Sanitária (ANVISA), lista que elenca as substâncias psicotrópicas de uso proscrito no Brasil e onde se encontram substâncias como a MDMA e o tetra-hidrocanabinol, princípio ativo da maconha. ${ }^{7}$

Entre os meses de janeiro e maio de 2008, o Laboratório de Toxicologia Forense do Núcleo de Perícias Criminalísticas de Campinas - Superintêndencia da Polícia Técnico-Científica do Estado de São Paulo recebeu para exame pericial 112 comprimidos de diferentes cores, tamanhos e formatos, oriundos de apreensões realizadas em Campinas e cidades adjacentes. Os exames químico-periciais realizados nestes comprimidos apresentaram resultados inesperados, diferentes daqueles obtidos quando a substância analisada é a MDMA - principal droga de abuso consumida na forma de comprimidos no Brasil.

Com base nos dados recentes sobre apreensões de comprimidos contendo mCPP em diversos países, como descrito anteriormente, foi iniciada uma investigação química para verificar se seria esta a substância ativa presente nos comprimidos encaminhados para exame pericial. Para isso, o material foi analisado por diferentes técnicas, como testes colorimétricos, cromatografia em camada delgada, cromatografia líquida de alta eficiência com detecção por arranjo de diodos e espectrometria de massas. O presente trabalho tem por objetivo apresentar e discutir os ensaios analíticos utilizados para caracterizar a substância presente nestes comprimidos.

\section{PARTE EXPERIMENTAL}

\section{Reagentes e soluções}

Soluções dos padrões ( $1 \mathrm{mg} / \mathrm{mL}$ em metanol) de anfetamina, metanfetamina, MDA, MDMA e cocaína, foram obtidas da Cerilliant (Round Rock, EUA). A água utilizada nos ensaios foi ultrapurificada em sistema Milli-Q (Millipore, Bedford, EUA). Todos os demais reagentes utilizados apresentavam pureza adequada para cromatografia líquida.

\section{Amostras}

Foram analisados 112 comprimidos apreendidos pela polícia civil do Estado de São Paulo e encaminhados para exame pericial no Laboratório de Toxicologia Forense do Núcleo de Perícias Criminalísticas de Campinas - Superintendência da Polícia Técnico Científica do Estado de São Paulo. Os comprimidos foram pesados individualmente em balança analítica e pulverizados em almofariz de porcelana. A partir do pó obtido, uma alíquota de $10 \mathrm{mg}$ foi pesada e transferida para balão volumétrico com capacidade de $10 \mathrm{~mL}$, ao qual foram adicionados 9 $\mathrm{mL}$ de metanol. $\mathrm{O}$ balão foi então submetido à agitação mecânica e banho ultrassônico por $10 \mathrm{~min}$, sendo posteriormente completado seu volume com o mesmo solvente (solução estoque da amostra). A partir desta solução, foram preparadas diferentes diluições a partir de uma concentração adequada para cada técnica analítica empregada.

\section{Equipamentos e condições analíticas}

\section{Ensaios preliminares}

Inicialmente, os comprimidos foram submetidos a testes colorimétricos comumente utilizados para triagem de drogas de abuso. ${ }^{8,9}$ Para realização do teste de Marquis, uma alíquota de $20 \mathrm{mg}$ de cada comprimido foi transferida para placa escavada de porcelana, sendo então adicionadas duas gotas do reagente de cor (ácido sulfúrico/ formaldeído 100:1, v/v), com imediata visualização da coloração obtida. ${ }^{9}$ Para o teste de Scott, uma alíquota de $20 \mathrm{mg}$ de cada comprimido foi transferida para placa escavada de porcelana, sendo então adicionadas uma gota de ácido clorídrico $0,1 \mathrm{~mol} / \mathrm{L}$ e uma gota do reagente de tiocianato de cobalto (solução aquosa $2 \% \mathrm{~m} / \mathrm{v}$ ).${ }^{10}$ No teste de Simons foram adicionadas uma gota do reagente A (nitroprussiato de sódio 1\%), uma gota do reagente B (acetaldeído etanólico 50\%) e uma gota do reagente $\mathrm{C}$ (carbonato de sódio $2 \%$ ). ${ }^{9}$

Para realização das análises por cromatografia em camada delgada de alta eficiência (CCDAE), uma alíquota de $50 \mu \mathrm{L}$ da solução estoque de amostra foi transferida para cromatoplacas de cromatografia em camada delgada de alta eficiência (Silica Gel G, 10 x 10 cm) (Merck, Darmstadt, Alemanha). Para verificar as características cromatográficas da substância investigada, as amostras foram analisadas em três condições distintas: separação cromatográfica com mistura de metanol/ amônia (100:1,5 v/v) seguida de visualização das bandas formadas após nebulização das cromatoplacas com reagente de iodoplatinato (solução aquosa de ácido cloroplatínico 0,2\% m/v + iodeto de potássio $2 \% \mathrm{~m} / \mathrm{v}$ ) e reagente de tiocianato de cobalto (preparado como descrito anteriormente); separação cromatográfica com utilização do sistemasolvente ciclo-hexano/tolueno/dietilamina (75:15:10 v/v) seguida por visualização das bandas formadas após nebulização das cromatoplacas com reagente de iodoplatinato e reagente de tiocianato de cobalto; separação cromatográfica com mistura de clorofórmio/acetona (4:1 v/v) seguido por visualização das bandas formadas após nebulização das placas com reagente de iodoplatinato e reagente Dragendorff iodado (solução aquosa de subnitrato de bismuto $0,2 \% \mathrm{~m} / \mathrm{v}$, iodeto de potássio $4 \% \mathrm{~m} / \mathrm{v}$, iodo $0,1 \% \mathrm{~m} / \mathrm{v}$, ácido acético $25 \% \mathrm{v} / \mathrm{v}){ }^{11}$

Cromatografia líquida de alta eficiência com detecção por arranjo de diodos (CLAE/DAD)

Foi utilizado equipamento de cromatografia líquida de alta eficiência LaChrom (Merck, Darmstadt, Alemanha) composto por bomba quaternária com sistema de desgaseificação da fase móvel (modelo L-7100), injetor automático (modelo L-7200), forno de coluna (modelo L-7300) e detector por arranjo de diodos (modelo L-7455). O controle do equipamento e a aquisição dos dados foram feitos através do software HSM (Merck, Darmstadt, Alemanha). As análises foram realizadas utilizandose coluna cromatográfica Zorbax Eclispse (C-18, 150 x 4,6 mm, com partículas de $5 \mu \mathrm{m}$, Agilent, Darmstadt, Alemanha), mantida a $30{ }^{\circ} \mathrm{C}$. A fase móvel utilizada foi constituída por (A) ácido fosfórico $10 \mathrm{mM}$ pH 3,0 (ajustado com trietilamina) e (B) acetonitrila, com eluição por gradiente. A composição da fase móvel variou em gradiente linear de fase aquosa-orgânica nas proporções de 95:5 a 10:90 v/v em 8 min, sendo mantida nesta condição por 2 min antes de retornar à condição inicial.

Antecedendo uma nova injeção, o sistema era mantido na condição inicial por 5 min para reequilíbrio. O fluxo da fase móvel foi mantido a 1,0 $\mathrm{mL} / \mathrm{min}$ durante toda a análise. Para sua utilização, a fase móvel foi filtrada através de membrana de acetato de celulose com poros de 0,45 $\mu$ m (Sartorius, Alemanha) e desgaseificada em banho ultrassônico por 5 min. A detecção foi realizada a 215 e 236 $\mathrm{nm}$, com a aquisição de espectros de varredura entre 190 e $450 \mathrm{~nm}$.

Para realização das análises, a solução estoque da amostra foi diluída 10 vezes com água ultrapurificada, filtrada em membrana com poros de $0,45 \mu \mathrm{m}$ e injetada no sistema CLAE/DAD (volume de injeção $=20 \mu \mathrm{L}$ ).

\section{Espectrometria de massas (EM/EM)}

Os espectros de massas foram obtidos em um espectrômetro de massas híbrido triplo quadrupólo - ion trap linear modelo 3200Qtrap (Applied Biosystems/MDS Sciex, Toronto, Canadá), utilizando fonte de ionização por electrospray (TurboIonSpray ${ }^{\circledR}$ ) em modo positivo. A tensão aplicada no capilar foi de $5500 \mathrm{~V}$, pressão do gás de nebulização de 15 psi (ar sintético), Curtain Gas ${ }^{\mathrm{TM}} 10$ psi (nitrogênio) e gás de colisão 6 psi (nitrogênio). A aquisição e o tratamento dos dados foram realizados com o software Analyst ${ }^{\circledR}$ versão 1.4.2 (Applied Biosystems/MDS Sciex, Toronto, Canadá). 
A solução estoque do material examinado foi diluída até se obter concentração igual a $200 \mathrm{ng} / \mathrm{mL}$, usando-se como diluente uma mistura metanol/água $(50 / 50, \mathrm{v} / \mathrm{v})$ contendo $5 \mathrm{mmol} / \mathrm{L}$ de formiato de amônio. Esta solução foi introduzida no espectrômetro de massas utilizando-se bomba de infusão do tipo seringa, com fluxo contínuo de $10 \mu \mathrm{L} / \mathrm{min}$.

\section{RESULTADOS E DISCUSSÃO}

O teste de Marquis é muito utilizado em laboratórios de química e toxicologia forense por fornecer resultados orientadores para diversas classes de fármacos e drogas de abuso de interesse forense, sendo o teste mais utilizado para triagem de derivados anfetamínicos, como a MDMA. ${ }^{9} \mathrm{O}$ material examinado permaneceu incolor, semelhante à cor apresentada pela cocaína, porém este resultado é muito diferente dos obtidos pelos padrões de anfetamina (laranja) e MDMA (preto).

Quando os comprimidos foram submetidos ao teste de Scott, usualmente utilizado para triagem de cocaína e outros anestésicos locais, observou-se o aparecimento de coloração azul na placa escavada. ${ }^{10,12}$ Este resultado diferiu daquele observado para a MDMA, que apresentou solução rósea com precipitados de coloração azulada.

No teste de Simons, o material examinado produziu coloração alaranjada nos primeiros segundos após o procedimento empregado, porém após cerca de 2 min houve alteração de cor, evidenciando-se uma modificação do alaranjado para o marrom-escuro, resultado esse que o diferencia dos resultados de cocaína (laranja) e MDMA (azul escuro). Os resultados dos testes de Marquis, Scott e Simons podem ser vistos resumidamente na Tabela 1 .

Tabela 1. Resultados obtidos nos testes colorimétricos utilizados como ensaios de triagem

\begin{tabular}{lccc}
\hline analíto & Marquis & Scott & Simons \\
\hline CPP & incolor & azul & $\begin{array}{c}\text { laranja (até 30 s) } \\
\text { marrom escuro } \\
\text { (pós 2 min) }\end{array}$ \\
MDMA & preto & rosa & azul escuro \\
cocaína & incolor & azul & laranja \\
\hline
\end{tabular}

A Tabela 2 apresenta os valores de Rf obtidos nos ensaios de triagem realizados por CCDAE. Os resultados mostraram que todos os sistemas solventes testados permitiram a completa separação da MDMA, cocaína e da substância presente nos comprimidos objetos de análise. Os três reveladores aplicados permitiram a boa visualização das bandas referentes às substâncias testadas, exceto quando o reagente de tiocianato de cobalto foi aplicado na cromatoplaca desenvolvida no sistema solvente composto por ciclo-hexano/tolueno/dietilamina $(75: 15: 10 \mathrm{v} / \mathrm{v})$, onde nenhuma mancha foi revelada.

Como pode ser observado na Figura 2, na condição cromatográfica utilizada nas análises por CLAE/DAD, a substância presente nos comprimidos investigados apresenta tempo de retenção de 7,4 min. Para verificar a seletividade do procedimento, $500 \mu \mathrm{L}$ da solução da amostra foram enriquecidos com igual volume de uma mistura de padrões de anfetamina, metanfetamina, MDA, MDMA e cocaína (concentração final dos padrões $=25 \mu \mathrm{g} / \mathrm{mL}$ ). Foi possível observar que o pico cromatográfico da substância investigada possui resolução completa quando comparado aos padrões injetados concomitantemente. Em função das diferentes absortividades das drogas de abuso testadas, os cromatogramas foram adquiridos em $215 \mathrm{~nm}$ (permitindo a visualização dos picos de anfetamina, metanfetamina, MDA, MDMA, da substância
Tabela 2. Valores de retenção relativa (Rf) obtidos nos ensaios de triagem realizados por cromatografia em camada delgada de alta eficiência

\begin{tabular}{lccc}
\hline analíto & $\begin{array}{c}\text { sistema solvente } \\
\text { ciclo-hexano: } \\
\text { metanol:amônia } \\
(100: 1,5)\end{array}$ & $\begin{array}{c}\text { tolueno:dietilamina } \\
(75: 15: 10)\end{array}$ & $\begin{array}{c}\text { clorofórmio: acetona } \\
(4: 1)\end{array}$ \\
\hline CPP & 0,32 & 0,58 & 0,21 \\
MDMA & 0,23 & 0,65 & 0,35 \\
cocaína & 0,58 & 0,72 & 0,42 \\
\hline
\end{tabular}

investigada e cocaína) e em $236 \mathrm{~nm}$. O segundo comprimento de onda é preferido se forem realizadas análises quantitativas, pois oferece linha de base mais estável, menos sujeita às flutuações decorrentes da mudança da composição da fase móvel durante a eluição por gradiente. Contudo, neste comprimento de onda (236 $\mathrm{nm}$ ) a detecção da anfetamina e metanfetamina ficou prejudicada em função da baixa absortividade destas substâncias neste comprimento de onda.
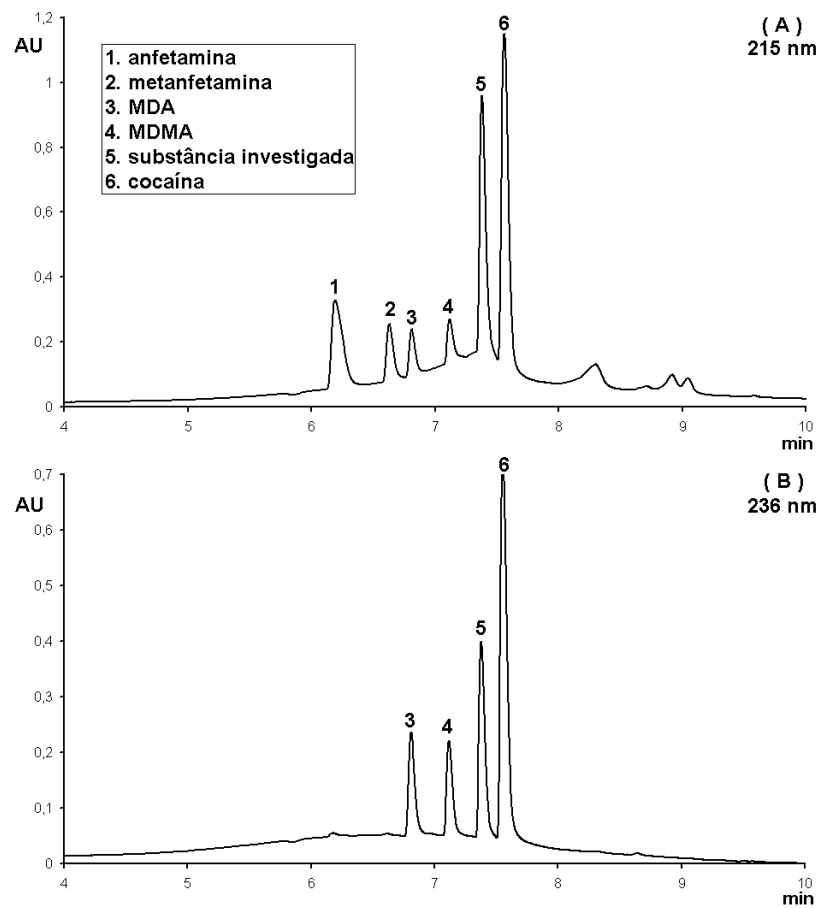

Figura 2. Cromatograma obtido pela injeção de mistura da diluição da solução estoque de amostra com mistura de padrões $(25 \mu \mathrm{g} / \mathrm{mL})$. Condições cromatográficas: coluna Zorbax Eclispse (C-18, $150 \times$ 4,6 mm, $5 \mu \mathrm{m})$, mantida a $30^{\circ} \mathrm{C}$; fase móvel: mistura de ácido fosfórico $10 \mathrm{mM} \mathrm{pH} \mathrm{3,0} \mathrm{(ajustado}$ com trietilamina) e acetonitrila (eluição por gradiente), vazão de 1,0 mL/ min; volume de injeção $20 \mu \mathrm{L}$; detecção realizada em 215 e $236 \mathrm{~nm}$, com a aquisição de espectros de varredura entre 195 e $450 \mathrm{~nm}$

A Figura 3 apresenta os espectros de absorção na região do UV/ VIS. A substância investigada apresenta significativa absorção em 208 e $248 \mathrm{~nm}$. O espectro UV/VIS da substância investigada apresenta significativa diferença quando comparado com os fornecidos por outras drogas testadas.

Os resultados obtidos por espectrometria de massas forneceram informações sobre o peso molecular do composto investigado, assim como seu perfil de fragmentação (EM/EM). Como pode ser observado na Figura 4, o espectro obtido em modo enhanced $M S$ com ionização em modo positivo apresentou dois picos 

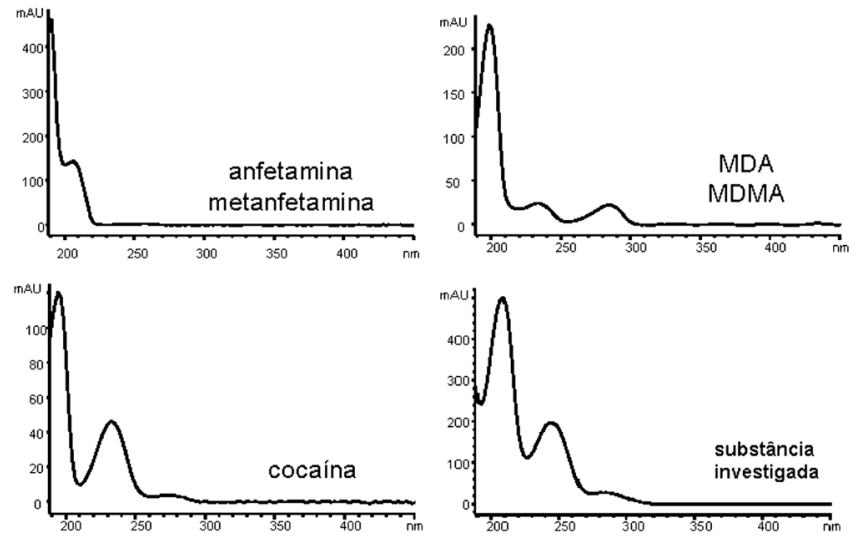

Figura 3. Espectros de absorção na região do ultravioleta-visível (190-450 nm) da anfetamina, metanfetamina, MDA, MDMA, cocaína e da substância presente nos comprimidos investigados

abundantes de relações massa/carga $(\mathrm{m} / \mathrm{z})$ iguais a 197,1 e 199,1. Esta informação é coerente com a estrutura química da CPP, que possui massa molar exata de 196,08 $\mathrm{g} / \mathrm{mol}$, com um isótopo de massa molar de 198,08 g/mol. Some-se a esta informação o fato de que estes picos apresentavam intensidades condizentes com a distribuição isotópica de substância que apresenta um átomo de cloro em sua estrutura, visto que este elemento químico está presente na natureza com abundância de $76 \%$ para o ${ }_{35} \mathrm{Cl}$ e $24 \%$ para $\mathrm{o}{ }_{37} \mathrm{Cl}$. Esta informação é confirmada quando o espectro obtido é sobreposto à distribuição isotópica teórica da $\mathrm{CPP}\left(\mathrm{C}_{10} \mathrm{H}_{14} \mathrm{ClN}_{2}\right)$, fornecida a partir do aplicativo Calculators presente no software Analyst $^{\circledR}$ 1.4.2. A distribuição isotópica teórica da CPP é apresentada na Figura 4 na forma de linhas tracejadas.

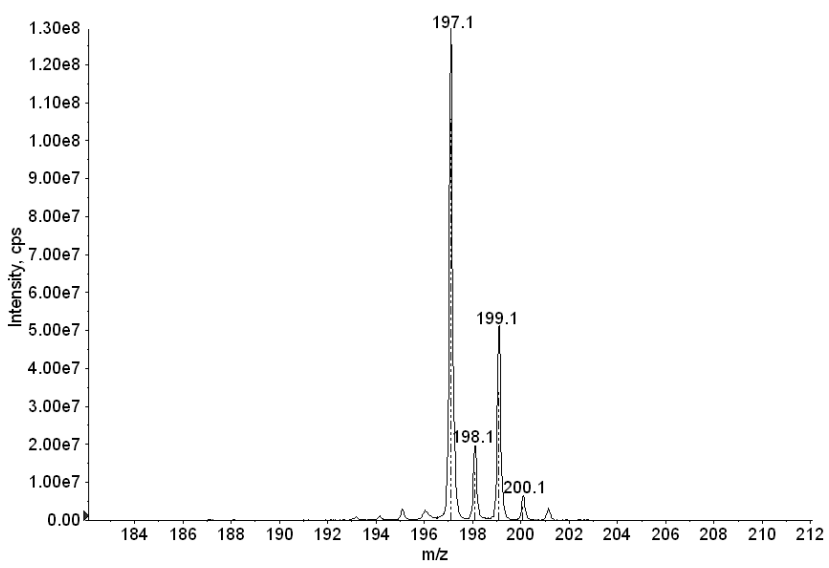

Figura 4. Espectro de massas obtido em enhanced MS (EM) do material encaminhado para análise pericial. A linha tracejada representa a distribuição isotópica teórica da $\mathrm{CPP}\left(\mathrm{C}_{10} \mathrm{H}_{14} \mathrm{ClN}_{2}\right)$. Condições analíticas: ionização por electrospray em modo positivo; infusão contínua $10 \mu \mathrm{L} / \mathrm{min}$; tensão do capilar $5500 \mathrm{~V}$; pressão do gás de nebulização (ar sintético) 15 psi. A solução analisada foi preparada como descrito no texto

Foram gerados espectros de massas (EM/EM) obtidos por dissociação induzida por colisão do íon precursor 197,1, com rampa de energia de colisão variando de 5 a $50 \mathrm{eV}$, utilizando nitrogênio como gás de colisão (6 psi). O espectro de massas acumulado é apresentado na Figura 5.

Esses resultados permitem concluir que a substância presente nos comprimidos investigados é a clorofenilpiperazina. Pelas técnicas

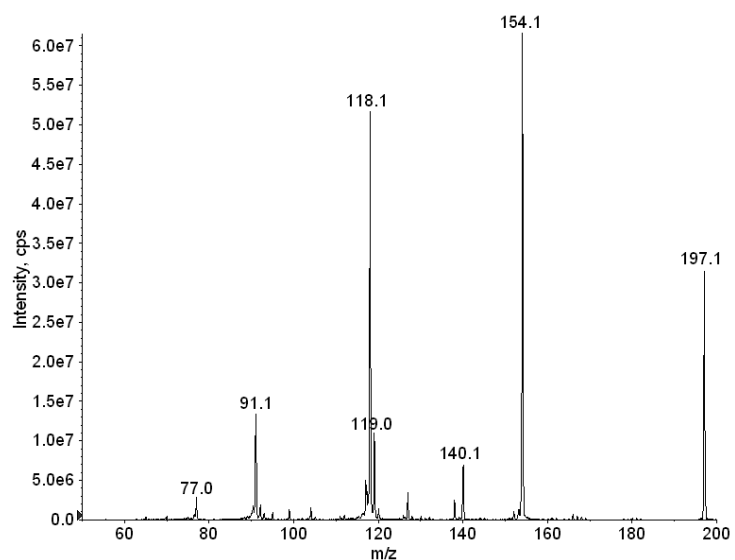

Figura 5. Espectro de massas acumulado (EM/EM) obtido por dissociação induzida por colisão do íon precursor 197,1. Condições analíticas: ionização por electrospray em modo positivo; infusão contínua $10 \mu \mathrm{L} / \mathrm{min}$; tensão do capilar 5500 V; pressão do gás de nebulização (ar sintético) 15 psi; rampa de energia de colisão de 5 a 50 eV; pressão do gás de colisão (nitrogênio) 6 psi. A solução analisada foi preparada como descrito no texto

analíticas utilizadas neste trabalho, não foi possível afirmar se nos comprimidos havia um único isômero ou uma mistura destes (oCPP, mCPP ou pCPP). Tal diferenciação seria possível empregando separações quirais (CLAE, cromatografia gasosa ou eletroforese capilar), espectroscopia na região do infravermelho ou ressonância magnética nuclear. Contudo, para fins legais, a diferenciação isomérica não é necessária, pois a RDC n.79/2008 menciona no adendo 1.1 da lista F2 que também devem ser controlados todos os sais e isômeros das substâncias elencadas na referida lista. ${ }^{7}$

De acordo com a literatura internacional, os isômeros pCPP e oCPP raramente são identificados em comprimidos apreendidos. Isto deve estar relacionado à ação farmacológica destes sobre o sistema nervoso central: a oCPP tem ação antagônica à mCPP sobre receptores de serotonina $5-\mathrm{HT}_{2 \mathrm{c}}$, produzindo efeitos completamente distintos e menos prazerosos do que seu análogo meta. ${ }^{3}$

Ainda no âmbito forense, com a confirmação de que a CPP já faz parte da lista de drogas de abuso consumidas no Brasil, torna-se necessário que os laboratórios de toxicologia forense estejam preparados para identificar a substância, assim como as intoxicações causadas por esta nova droga de abuso. Como a mCPP pode estar presente em fluidos biológicos como produto da biotransformação de fármacos como a trazodona, a interpretação do resultado analítico deve ser criteriosa, para correta diferenciação entre o uso recreacional (onde a trazodona não estará presente) e o uso terapêutico do fármaco antidepressivo. ${ }^{5,6}$ Em intoxicações agudas por mCPP, as concentrações plasmáticas da droga são aproximadamente seis vezes maiores do que a concentração usual encontrada em pacientes sob tratamento com trazodona. ${ }^{2}$

Alguns autores reportam que a MDMA e a cocaína podem estar presentes em comprimidos de mCPP ou serem usadas em combinação com este..$^{3-5}$ Por esta razão, é de grande importância que o procedimento analítico empregado avalie a presença das três substâncias. Dos procedimentos descritos no presente trabalho, pode-se observar que os testes colorimétricos não foram suficientes para diferenciar de modo inequívoco a CPP da cocaína. Através da combinação dos valores de Rf em diferentes sistemas solventes e na coloração obtida com reveladores distintos, foi possível diferenciar de modo inquestionável as três substâncias. A diferenciação pode ser feita ainda pelo sistema CLAE/DAD aqui apresentado, agregando neste caso a informação do espectro UV-Vis, de características muito distintas para as três substâncias. 


\section{CONCLUSÕES}

O surgimento de novas drogas de abuso, em especial as sintéticas, tem aumentado drasticamente nos últimos anos. Os laboratórios de análise pericial frequentemente enfrentam limitações quanto ao acesso a padrões analíticos certificados de substâncias proscritas e/ ou de uso controlado. Além de reportar a primeira apreensão da CPP no Estado de São Paulo, este artigo mostrou que é possível identificar de maneira confiável novas substâncias encaminhadas para perícia, mesmo sem a presença de padrões analíticos, desde que se lance mão de diferentes procedimentos e técnicas analíticas, que forneçam informações complementares e, também, subsídios técnicos para a realização da perícia químico-forense.

\section{REFERÊNCIAS}

1. http://www.unodc.org/unodc/en/data-and-analysis/WDR-2008.html, acessada em Fevereiro 2010.

2. Kovaleva, J.; Devuyst, E.; Paepe, P. D.; Verstraete, A.; Ther. Drug Monit. 2008, 30, 394 .
3. http://www.emcdda.europa.eu/publications/drug-profiles/bzp, acessada em Fevereiro 2010

4. Bossong, M. G.; Dijk, J. P. V.; Niesink, R. J. M.; Addiction Biology 2005, 10, 321 .

5. Staack, R. F.; Paul, L. D.; Schmid, D.; Roider, G.; Rolf, B.; J. Chromatogr, B 2007, 855, 127.

6. Patel, B. N.; Sharma, N.; Sanyal, M.; Shrivastav, P. S.; J. Chromatogr., B 2008, 871, 7. http://e-legis.anvisa.gov.br/leisref/public/showAct. php?id=33987\&word=, acessada em Março 2009.

8. http://www.ncjrs.gov/pdffiles1/nij/183258.pdf, acessada em Março 2009.

9. Jeffrey, W. Em Clarke's analysis of drugs and poisons in pharmaceuticals, body fluids and postmortem material; Moffat, A. C.; Osselton, M. D.; Widdop, B., eds.; Pharmaceutical Press: London, 2003, p. 279.

10. Tsumura, Y.; Mitome, T.; Kimoto, S.; Forensic Sci. Int. 2005, 155, 158.

11. Poole, C. F. Em ref. 9, p. 392.

12. Oguri, K.; Sachiko W.; Shuichi, E.; Hideyuki, Y.; Japanese J. Toxicol. Environ. Health. 1995, 41, 274. 44. 